\title{
The analgesic efficacy of bilateral superficial cervical plexus block for thyroid surgery under general anesthesia: a prospective cohort study
}

\author{
Yophtahe B. Woldegerima* ${ }^{*}$, Amare G. Hailekiros and Girmay L. Fitiwi
}

\begin{abstract}
Objective: Uses of simple analgesics were found insufficient to manage pain after thyroid surgery. We hypothesized that using bilateral superficial cervical plexus block (BSCPB) might influence the pattern of immediate postoperative pain and analgesic consumption. The general objective of the study was to assess the analgesic efficacy of bilateral superficial plexus block for thyroid surgery under general anesthesia.
\end{abstract}

Results: A total of 74 willing patients involved. Half of them had received BSCPB with $10 \mathrm{ml}$ of $0.25 \%$ bupivacaine just before induction and the remaining half did not. Postoperatively, patients were assessed at immediate, 2nd, 6th, 12th and 24th h. At all endpoints, NRS-11 scores for pain were significantly lower in the block group. The time to first analgesic requirement was significantly longer $132.3 \pm 71.5 \mathrm{~min}$ vs $71.4 \pm 60.0 \mathrm{~min}, \mathrm{p}=0.009$. Opioid and total analgesic consumption were reduced by BSCPB in the first 24 postoperative hours. There was low but non-significant rate of PONV in the block group. No clinically important adverse event was noted related to BSCPB.

Trial registration The study was registered in Pan African Clinical Trial Registry on 13/01/2020 and the registration number is PACTR202001579588451. Retrospectively registered.

Keywords: Bilateral superficial cervical plexus block, Postoperative pain, Thyroidectomy, Cervical plexus, Multimodal analgesia

\section{Introduction}

Thyroid disease is one of the major public health problems in Ethiopia [1-3]. Hence, thyroid surgery is one of the frequently performed surgical procedures. It is also the leading endocrine surgery world-wide [4]. The prevalence of goiter among school children in Ethiopia was estimated between 20 and $50 \%$ and even more. It was explained by iodine deficiency [1-3]. Despite this huge implication and frequency of thyroid surgery, the analgesic efficacy of bilateral superficial plexus block for thyroid

*Correspondence: yophtii@gmail.com

Department of Anesthesia, College of Medicine and Health Sciences, University of Gondar, Gondar 196, Ethiopia surgery was not determined in our population. In addition to the differences in the patterns of thyroid diseases in our population, it's strongly suggested that pain severity and perception have significant differences among populations worldwide [5]. Most of previously published studies were done in different population. Furthermore, the surgical and anesthetic service settings in Africa have big differences compared to the developed world including interpersonal and technical differences. The developing world has many barriers for appropriate management of acute pain in where only $7 \%$ of opioid consumed from the global consumption [5].

Acute pain is one of the commonest complaints in the postoperative period which has serious adverse 
cardiovascular, pulmonary, metabolic and psychological outcomes [5-8]. Pain after thyroid surgery is significant especially in the early postoperative hours. The mean score of post-thyroidectomy pain was $6.9 \pm 1.7$ on visual analog scale and $90 \%$ of patients required morphine [9]. Despite paracetamol administration, $70 \%$ of patients initially rate a score $\geq 4$ on numeric rating scale (NRS-11) [10]. Recently, a study has shown that $93 \%$ of patients required up to 20 oral morphine equivalents [4].

Simple analgesics such as paracetamol and non-steroidal anti-inflammatory drugs (NSAIDs) were found insufficient to manage pain after thyroidectomy [11]. Bilateral superficial cervical plexus block (BSCPB) is widely used for managing pain after thyroid surgery. Studies reported that the block allowed to reduce anesthetic requirements and provided prolonged postoperative analgesia. It also decreased pain score, rescue analgesic requirement and overall opioid requirement in the first 24 postoperative hours [12-14]. Hence, it minimizes opioids related adverse outcomes and cost [15]. BSCPB was found simple, safe, cheap and effective for post-thyroidectomy pain management [16]. However, ineffectiveness of BSCPB was also reported [17-19].

We hypothesized that using BSCPB may influence the pattern of immediate postoperative pain and analgesic consumption. The general objective of the study was to assess the analgesic efficacy of bilateral superficial plexus block for thyroid surgery under general anesthesia.

\section{Main text}

\section{Methodology}

\section{Study design, area, period and population}

A prospective cohort study was conducted in University of Gondar Hospital (UoGH), Northwest Ethiopia from February to June 2016. The study was registered in Pan African Clinical Trial Registry (PACTR202001579588451). All adult (18+) ASA I and II patients who undergone thyroidectomy at the hospital during the study period were included in the study. Patients who have refused to participate, allergic history for local anesthetics, retro-sternal goiter, altered anatomical landmarks, coagulation abnormality and other contraindications for the block were excluded.

\section{Variables}

Pain severity, time to first analgesic request and total $24 \mathrm{~h}$ analgesics consumption were outcome variables. Sociodemographic, ASA class, size and type of thyroid mass and duration of anesthesia and surgery were some of the independent variables.

\section{Sample size determination and sampling technique}

The sample size was determined by postoperative morphine requirement in the first $24 \mathrm{~h}$. BSCPB with $0.25 \%$ of bupivacaine reduced morphine requirement $(\mathrm{mg} / \mathrm{Kg})$ in the first 24 postoperative hours by nearly $55 \%$ median in $\mathrm{mg} / \mathrm{Kg}(0.38$ Vs 0.69, $\mathrm{p}=0.01)$ [20]. Calculation was done using predetermined $5 \%$ margin of error $(\alpha)$, and power of $80 \%(\beta), \int(\alpha, \beta)$ is 7.85 .

$$
\begin{aligned}
\text { Patients per group } & =\frac{x 1(1-x 1)+x 2(1-x 2)}{(x 1-x 2)^{2}} \times \int(\alpha \beta) \\
& =\frac{0.69(1-0.69)+0.38(1-0.38)}{(0.69-0.38)^{2}} \times 7.85 \\
& =36.7 \approx 37 \text { patients in each group }
\end{aligned}
$$

The patients in the block group had received BSCPB with $10 \mathrm{ml}$ of $0.25 \%$ bupivacaine on each side along the posterior border of sternocleidomastoid (from the midpoint $2 \mathrm{ml}$ to caphal $4 \mathrm{ml}$ and caudal $4 \mathrm{ml}$ ) immediately before induction. The patients in non-block group did not receive $\mathrm{BSCPB}$ and placebo injection of normal saline was not done.

\section{Data collection, quality control and analysis}

Two data collectors were assigned. One for pre- and intraoperative time, and another for postoperative time to facilitate blinding. Assessments were done at postoperatively in the recovery room; immediately after arrival, 2nd, 6th, 12th and 24th h. Postoperative pain was assessed using NRS-11. First analgesia request time, and total analgesia consumption within $24 \mathrm{~h}$ were documented. Data was checked and analyzed by SPSS-20 (IBM Corporation). Normality was checked by Shapiro-Wilk test. An independent t-test was performed to compare time to first analgesic request. Mann-Whitney $\mathrm{U}$ test was used to analyze repeated NRS-11 scores and total postoperative analgesic consumption. Normally distributed data was presented in mean $\pm S D$ whereas non-normally distributed data was presented as median (IQR). A p-value $<0.05$ was considered as statistically significant.

\section{Results}

Demographic, anthropometric and clinical characteristics of participants

A total of 74 patients (34 in each group) were involved. The demographic, anthropometric and clinical characteristics of participants were found comparable between the groups (Table 1). Sub-total and near total thyroidectomy were the leading types of thyroid surgery in the block group and non-block group respectively. The length of incision was $9.2 \pm 2.8$ vs $9.1 \pm 2.1$ in the block group and non-block group respectively and no statistically significant difference between the groups. Simple 
Table 1 Demographic and clinical characteristics of patients, frequency and percentage (n (\%)) from Chi square test, mean \pm standard deviation from independent t-test, $\mathrm{N}=74$

\begin{tabular}{|c|c|c|c|}
\hline Variables & Block group $(n=37)$ & Non-block group $(n=37)$ & $p$-value \\
\hline Age (years) & $35.1 \pm 9.3$ & $34.6 \pm 10.0$ & 0.85 \\
\hline $\mathrm{BMl}$ & $20.1 \pm 2.4$ & $20.4 \pm 3.3$ & 0.74 \\
\hline Sex & & & 0.30 \\
\hline Male & $10(27)$ & $6(16.3)$ & \\
\hline Female & $27(73)$ & $31(83.7)$ & \\
\hline ASA class & & & 0.99 \\
\hline 1 & $30(81)$ & $30(81)$ & \\
\hline$\|$ & $7(19)$ & $7(19)$ & \\
\hline Diagnosis & & & 0.63 \\
\hline Simple nodular goiter & $22(59.4)$ & $12(32.4)$ & \\
\hline Simple colloid goiter & $6(16.2)$ & $6(16.2)$ & \\
\hline Multi-nodular goiter & $8(21.6)$ & $16(43.2)$ & \\
\hline Thyroid cancer & $1(2.7)$ & $3(8.1)$ & \\
\hline Size of thyroid mass $\left(\mathrm{cm}^{2}\right)$ & $31.8 \pm 24.2$ & $37.5 \pm 26.2$ & 0.43 \\
\hline Type of thyroidectomy & & & 0.12 \\
\hline Lobectomy & $0(0)$ & $0(0)$ & \\
\hline Subtotal & $22(59.4)$ & $12(32.4)$ & \\
\hline Near total & $12(32.4)$ & $21(56.7)$ & \\
\hline Total & $2(5.4)$ & $1(2.7)$ & \\
\hline Extended neck dissection & $1(2.7)$ & $3(8.1)$ & \\
\hline Incision length (cm) & $9.2 \pm 2.8$ & $9.1 \pm 2.1$ & 0.96 \\
\hline Duration of surgery (min) & $120.2 \pm 36.6$ & $123.4 \pm 41.4$ & 0.77 \\
\hline Duration of anesthesia & $140.4 \pm 38.0$ & $145.6 \pm 43.8$ & 0.66 \\
\hline Preemptive analgesia at induction & & & 0.57 \\
\hline Acetaminophen and diclofenac & $4(16)$ & $3(12)$ & \\
\hline Acetaminophen, diclofenac and opioids & $21(84)$ & $22(88)$ & \\
\hline
\end{tabular}

nodular goiter was the most frequent (22; 59.4\%) diagnosis in the block group and multi-nodular goiter in the non-block group $(16 ; 43.2 \%)$. Only 4 patients ( 1 in block group and 3 in non-block group) had undergone extended neck dissection. The use of preemptive analgesia with simple analgesics and opioids was comparable. There was no difference in choices of induction agents.
The larger proportions of patients in both groups were induced with propofol (block group $=75.7 \%$ vs nonblock group $=67.6 \%, \mathrm{p}>0.05)$ and the remaining with thiopentone.

Table 2 Postoperative numeric rating scale-11 pain scores: median (IQR), and first analgesic request time: mean \pm standard deviation from Mann-Whitney U-test

\begin{tabular}{lllr}
\hline Group & Block group $(\mathbf{n}=\mathbf{3 7})$ & Non-block group $(\mathbf{n}=\mathbf{3 7})$ & $\mathbf{p}$-value \\
\hline NRS-11 at immediate postoperative time & $0(5)$ & $6(4)$ & 0.001 \\
NRS-11 at 2nd $h$ & $2(6)$ & $7(2)$ & $<0.001$ \\
NRS-11 at 6th $h$ & $2(4)$ & $5(3)$ & 0.001 \\
NRS-11 at 12th $h$ & $0(3)$ & $4(3)$ & $<0.001$ \\
NRS-11 at 24th $h$ & $0(1)$ & $3(3)$ & $<0.001$ \\
First analgesic request time (min) & $132.3 \pm 71.5$ & $71.4 \pm 60.0$ & 0.009 \\
\hline
\end{tabular}

$\mathrm{N}=74$

${ }^{a}$ Independent t-test 


\section{Patterns of pain and analgesic requirements}

At all endpoints, pain scores were significantly lower in the block group. Furthermore, the first analgesic request time was significantly longer in the block group than the non-block group (Table 2). The total analgesic consumption in the first 24 postoperative hours was significantly reduced in the group that received BSCPB. Surprisingly, none of patients in the block group required strong opioid analgesics. However, $24 \mathrm{~h}$ pethidine consumption was $34 \pm 15.1 \mathrm{mg}$ in the non-block group (Table 3 ).

\section{Discussion}

We found statistically significant reduction in mean NRS-11 scores at all end-points in the block group. The time to first analgesic requirement was nearly doubled in the block group (132.3 $\pm 71.5 \mathrm{~min}$ vs $71.4 \pm 60.0 \mathrm{~min}$, $\mathrm{p}=0.009)$. Multiple studies have investigated the effectiveness of BSCPB in thyroid surgery and reported that it was effective in minimizing pain scores, opioid and total analgesic consumption and prolonging analgesia duration [12, 13, 21, 22]. A meta-analysis of 14 studies incorporated 1154 patients revealed BSCPB significantly reduced analgesic requirement, VAS scores and lengthen time to first analgesic request [14]. BSCPB was found significantly associated with nearly half shorter postoperative hospital staying days $(2.4 \pm 0.6$ vs $4.7 \pm 1.6 ; \mathrm{p}<0.05)$ [12].

In-contrast, some studies denied the effectiveness of BSCPB. The block had failed to demonstrate reduction in pain scores and opioid consumption. But longer time for first analgesic request was observed. They explained the result by pain arising from deeper and muscular structures, pain from positioning and wound drainages [17]. Despite these, pain after thyroidectomy was known to have large superficial component [23]. Different drug regimens, volumes, techniques of injections and duration of postoperative follow-up ( $36 \mathrm{~h}$ ) might be possible causes for these contradictory conclusions [18]. Another study has concluded equi-vocal as BSCPB reduced pain intensity and analgesic requirement but could not provide optimal pain relief alone since $65 \%$ of patients need additional analgesia [10]. Performing the block after the surgery might have effect on this equi-vocal outcome.

Table 3 Total postoperative analgesic consumption: mean \pm standard deviation from Mann-Whitney U-test

\begin{tabular}{llrr}
\hline Group & Block group $(\mathbf{n = 3 7 )}$ & $\begin{array}{l}\text { Non-block } \\
\text { group }(\mathbf{n = 3 7 )}\end{array}$ & p-value \\
\hline Diclofenac (mg) & $75 \pm 0$ & $82 \pm 24.2$ & 0.003 \\
Tramadol (mg) & $90 \pm 22.4$ & $104.55 \pm 37.5$ & 0.004 \\
Pethidine (mg) & 0 & $34 \pm 15.1$ & 0.001 \\
\hline $\mathbf{N}=\mathbf{7 4}$ & & &
\end{tabular}

In another study, hospital stay and postoperative analgesic consumption were comparable even if patients in the block group had lesser VAS scores. These differences might be due to 4 days follow-up [24].

In this study, all blocks were done by landmark technique by subcutaneous deposition of local anesthetic along the posterior borders of sternocleidomastoid muscles on both sides of the neck. In a recent Egyptian study that compared landmark and ultrasound-guided techniques found no difference in effectiveness and safety [25]. However, another study has concluded that an ultrasound-guided technique had superiority and explained by direct visualization of the nerves, adjacent structures and needle movement that results in faster, denser and longer block [26].

Performing regional nerve blocks and administration of multi-modal analgesics prior to surgical incision are helpful in reducing intra- and postoperative opioid consumption, primary hyperalgesia, central sensitization and chronic pain [14, 23, 27]. In combination with gabapentin, BSCPB has prevented delayed neuropathic pain at 6th postoperative month [28]. Thyroidectomy without BSCPB was three-times likely associated with neuropathic pain compared to thyroidectomy with BSCPB [29]. In our study, all BSCPBs were done in the preoperative time, immediately before induction as a part of multi-modal analgesia. This might provide the benefits of preemptive analgesia and minimized anesthetic duration. Some surgeons complained for disruption of the surgical anatomy by the block. In another study, according to surgeon's opinions, the surgical conditions were very good and had encountered no problem [23]. An ultrasoundguided study suggested that performing $\mathrm{BSCPB}$ in the pre- or postoperative time were equally effective. Landmark technique was also found effective whether performed in the pre- or postsurgical time to reduce the VAS scores [24]. Furthermore, presurgical block is technically easier unless in very large thyroid mass. After surgery, anatomical planes may be changed and facilitate leakage through incision and facial layers [13]. However, Herbland and colleagues reported that irrespective of time of injection (pre- or postsurgical), BSCPB is not effective analgesic option for thyroidectomy. They explained it by incomplete sensory block because of limited spread of solution through the investing fascia and high vascularity of the area [18].

Wound infiltration is effective choice of analgesia after thyroid surgery. But compared to BSCPB, the later was found more effective. Time to first analgesia were $162 \pm 124 \mathrm{~min}$ vs $544 \pm 320 \mathrm{~min}$ vs $860 \pm 59 \mathrm{~min}$ in control, wound infiltration and BSCPB groups respectively; $\mathrm{p}<0.001$ [30]. This analgesic duration was very long compared to our finding. This difference might be due to drug 
regimen as they used $15 \mathrm{ml}$ of $0.5 \%$ bupivacaine and in the current study $10 \mathrm{ml}$ of $0.25 \%$ bupivacaine. Two recent RCTs have declared that wound infiltration lacks effectiveness for treating pain after thyroidectomy; even in addition of adrenaline [31, 32].

The incidences of postoperative nausea and vomiting (PONV) after thyroidectomy ranges from $21.7 \%$ up to $84 \%[12,33]$. We have assessed PONV with simplified PONV impact scale and the incidence of clinically important PONV was $27 \%$ in block group and $35.1 \%$ in non-block group but no statistically significant difference was observed. These results were lower compared to other studies. The reason might be predominant use of propofol for induction of anesthesia in the current study [18]. Despite lower incidences of PONV, we found that comparable between the groups. This phenomenon might be explained by tramadol consumption. Even though, there was statistically significant reduction in tramadol consumption, patients in the block group might have consumed clinically significant amount of tramadol. No clinically significant complication occurred in association with BSCPB.

We have concluded that BSCPB has significantly reduced pain scores, opioid and total analgesic consumption and prolong the time to first analgesic requirement. We recommend that BSCPB is simple and can be used effectively and safely for pain management after thyroid surgery as a part of multi-modal analgesia in the first 24 postoperative hours.

\section{Limitations}

As a cohort study, the confounders might not be adequately controlled. We also have not studied the impact of the block on intraoperative analgesic and anesthetic requirements.

\section{Abbreviations \\ ASA: American society of anesthesiologists; BSCPB: bilateral superficial cervical plexus block; IBM: International Business Machines; IQR: interquartile range; NRS-11: 11-points numeric rating scale; NSAIDs: non-steroidal anti-inflam- matory drugs; PONV: postoperative nausea and vomiting; RCTs: randomized control trials; SPSS-20: statistical package for social studies 20th version; SD: standard deviation; UoGH: University of Gondar Hospital.}

\section{Acknowledgements}

We would like to thank University of Gondar and the data collectors in advance.

\section{Authors' contributions}

AGH, YBW conceptualized the topic and objectives. AGH designed the study. GLF participated in data and statistical analyses. YBW critically revised the results and scientific contents, and led the manuscript preparation. All authors read and approved the final manuscript.

\section{Funding}

College of Medicine and Health Sciences, University of Gondar has helped the study by providing consumables and stationaries. The institution has no any competing interests in the study.

\section{Availability of data and materials}

Data and materials used in this study are available and can be presented by the corresponding author upon reasonable request.

\section{Ethics approval and consent to participate}

Ethics approval was obtained from ethical review committee in Department of Anesthesia, College of Medicine and Health Science, University of Gondar. Signed informed consent was obtained from each study subject after clear explanation. Decisions of refused patients were respected. Participants had the right to withdraw any time from the study. When patients complained for pain, corresponding care providers were informed to administer rescue analgesia depending on the severity. Confidentiality was guaranteed.

\section{Consent for publication}

Not applicable; the article did not include any personal or clinical details of any participant.

\section{Competing interests}

The authors declared they have no competing interests.

Received: 13 November 2019 Accepted: 14 January 2020

Published online: 28 January 2020

\section{References}

1. Berhanu N, Woldemichael K, Bezabih M. Endemic goiter in school children in southwestern Ethiopia. Ethiop J Health Dev. 2004;18(3):175-8.

2. Enyew HD, Zemedkun KG, Dagnaw AM. Prevalence of goiter and associated factors among primary school children aged $6-12$ years old in Goba Town, South East, Ethiopia. Int J Nutr Food Sci. 2015;4(3):381-7.

3. Mola M, Getu D, Haimanot $H$. Prevalence of associated factors of goiter among rural children aged 6-12 years old in North-West Ethiopia. BMC Public Health. 2014;14:130.

4. Lou I, Chennell TB, Schaefer SC, Chen H, Sippel RS, Balentine C, et al. Optimizing outpatient pain management after thyroid and parathyroid surgery: a two-institution experience. Ann Surg Oncol. 2017;24(7):1951-7.

5. Ballantyne J, Cousins M, GM. Managing acute pain in the developing World. Int Assoc Study Pain. 2011;19(3):1-6.

6. Joshi G, Ogunnaike B. Consequences of inadequate postoperative pain relief and chronic persistent postoperative pain. Anesthesiol Clin North Am. 2005;23:21

7. Kehlet H. Multimodal approach to control postoperative pathophysiology and rehabilitation. Br J Anaesth. 1997;78:606.

8. Rowlingson J. Update on acute pain management. International Anesthesia Research Society Review Course Lectures. 2006;95.

9. Gozal Y, Shapira S, Gozal D, Magora F. Bupivacaine wound infiltration in thyroid surgery reduces postoperative pain and opioid demand. Acta Anaesthesiol Scand. 1994;38:813-5.

10. Dieudonne N, Gomola A, Bonnichon P, Ozier YM. Prevention of postoperative pain after thyroid surgery: a double-blind randomized study of bilateral superficial cervical plexus blocks. Anesth Analg. 2001;92(6):1538-42.

11. Motamed C, Merle J, Yakhou L, Combes X, Vodinh J, Kouyoumoudjian C, et al. Postoperative pain scores and analgesic requirements after thyroid surgery: comparison of three intraoperative opioid regimens. Int J Med Sci. 2006;3(1):11.

12. Çanakçı E, Taş N, Yağan Ö, Genç T. Effect of bilateral superficial cervical block on postoperative analgesia in thyroid surgery performed under general anesthesia. Ege J Med. 2015;54(4):182-6.

13. Kale S, Aggarwal S, Shastri V. Evaluation of the analgesic effect of bilateral superficial cervical plexus block for thyroid surgery: a comparison of presurgical with postsurgical block. Indian J Surg. 2015;77(3):1196-200.

14. Mayhew D, Sahgal N, Khirwadkar R, Hunter JM, Banerjee A. Analgesic efficacy of bilateral superficial cervical plexus block for thyroid surgery: meta-analysis and systematic review. Br J Anaesth. 2018;120(2):241-51. 
15. Paulozzi LJ, Budnitz DS, Xi Y. Increasing deaths from opioid analgesics in the United States. Pharmacoepidemiol Drug Saf. 2006;15(9):618-27.

16. Kolawole I, Rahman G. Cervical plexus block for thyroidectomy. S Afr J Anaesth Analg. 2003;9(5):10-7.

17. Eti Z, Irmak P, Gulluoglu BM, Manukyan MN, Gogus FY. Does bilateral superficial cervical plexus block decrease analgesic requirement after thyroid surgery? Anesth Analg. 2006;102(4):1174-6.

18. Herbland A, Cantini O, Reynier P, Valat P, Jougon J, Arimone $Y$, et al. The bilateral superficial cervical plexus block with $0.75 \%$ ropivacaine administered before or after surgery does not prevent postoperative pain after total thyroidectomy. Reg Anesth Pain Med. 2006;31(1):34-9.

19. Sardar K, Rahman S, Khandoker M, Amin Z, Pathan F, Rahman M. The analgesic requirement after thyroid surgery under general anaesthesia with bilateral superficial cervical plexus block. Mymensingh Med J. 2013;22(1):49-52.

20. Karthikeyan VS, Sistla SC, Badhe AS, Mahalakshmy T, Rajkumar N, Ali SM, et al. Randomized controlled trial on the efficacy of bilateral superficial cervical plexus block in thyroidectomy. Pain Pract. 2013;13(7):539-46.

21. Andrieu G, Amrouni H, Robin E, Carnaille B, Wattier J, Pattou F, et al. Analgesic efficacy of bilateral superficial cervical plexus block administered before thyroid surgery under general anaesthesia. Br J Anaesth. 2007;99(4):561-6.

22. Shih M-L, Duh Q-Y, Hsieh C-B, Liu Y-C, Lu C-H, Wong C-S, et al. Bilateral superficial cervical plexus block combined with general anesthesia administered in thyroid operations. World J Surg. 2010;34(10):2338-43.

23. Suh Y-J, Kim YS, In JH, Joo JD, Jeon Y-S, Kim H-K. Comparison of analgesic efficacy between bilateral superficial and combined (superficial and deep) cervical plexus block administered before thyroid surgery. Eu J Anaesthesiol. 2009;26(12):1043-7.

24. Steffen T, Warschkow R, Brändle M, Tarantino I, Clerici T. Randomized controlled trial of bilateral superficial cervical plexus block versus placebo in thyroid surgery. Br J Surg. 2010;97(7):1000-6.

25. Hassan RM, Hashim RM. Analgesic efficacy of ultrasound guided versus landmark-based bilateral superficial cervical plexus block for thyroid surgery. Egypt J Anaesth. 2017;33(4):365-73.
26. Senapathi TGA, Widnyana IMG, Aribawa IGNM, Wiryana M, Sinardja IK, Nada IKW, et al. Ultrasound-guided bilateral superficial cervical plexus block is more effective than landmark technique for reducing pain from thyroidectomy. J Pain Res. 2017;10:1619.

27. Ahiskalioglu A, Yayik AM, Ahiskalioglu EO, Dostbil A, Doymus O, Karadeniz E, et al. Ultrasound-guided bilateral superficial cervical block and preemptive single-dose oral tizanidine for post-thyroidectomy pain: a randomized-controlled double-blind study. J Anesth. 2018;32:219-26.

28. Brogly N, Wattier J-M, Andrieu G, Peres D, Robin E, Kipnis E, et al. Gabapentin attenuates late but not early postoperative pain after thyroidectomy with superficial cervical plexus block. Anesth Analg. 2008;107(5):1720-5.

29. Wattier J-M, Calazzo R, Andrieu G, Kipnis E, Pattou F, Lebuffe G. Chronic post-thyroidectomy pain: incidence, typology, and risk factors. Anaesth Crit Care Pain Med. 2016;35:197.

30. El-Taleb SS, Nagi M, Al-Mansoury A-h, Al-Shokri R, Lfeituri MA, Qutait M. Two different approaches for prevention of post-thyroidectomy pain: local wound infiltration versus bilateral superficial cervical plexus block. Libyan J Surg. 2016:4:1-11.

31. Mismar AA, Mahseeri MI, Al-Ghazawi MA, Obeidat FW, Albsoul MN, Al-Qudah MS, et al. Wound infiltration with bupivacaine $0.5 \%$ with or without adrenaline does not decrease pain after thyroidectomy: a randomized controlled study. Saudi Med J. 2017;38(10):994.

32. Miu M, Royer C, Gaillat C, Schaup B, Menegaux F, Langeron O, et al. Lack of analgesic effect induced by ropivacaine wound infiltration in thyroid surgery: a randomized, double-blind, placebo-controlled trial. Anesth Analg. 2016;122(2):559-64.

33. Cai H, Lin C, Yu C, Lin X. Bilateral superficial cervical plexus block reduces postoperative nausea and vomiting and early postoperative pain after thyroidectomy. J Int Med Res. 2012;40(4):1390-8.

\section{Publisher's Note}

Springer Nature remains neutral with regard to jurisdictional claims in published maps and institutional affiliations.
Ready to submit your research? Choose BMC and benefit from:

- fast, convenient online submission

- thorough peer review by experienced researchers in your field

- rapid publication on acceptance

- support for research data, including large and complex data types

- gold Open Access which fosters wider collaboration and increased citations

- maximum visibility for your research: over $100 \mathrm{M}$ website views per year

At BMC, research is always in progress.

Learn more biomedcentral.com/submissions 